\title{
Passion and Gambling: Investigating the Divergent Affective and Cognitive Consequences of Gambling1
}

\author{
GeneViève A. MAgeau, Robert J. VAllerand, ${ }^{2}$ \\ FranÇOIS L. ROUSSEAU, CATHERINE F. RATELLE, AND \\ PIERRE J. PROVENCHER \\ Laboratoire de recherche sur le comportement social \\ Université du Québec à Montréal \\ Montréal, Québec, Canada
}

\begin{abstract}
Vallerand et al. (2003) developed a theoretical framework of passion where two types of passions are proposed: obsessive and harmonious passion. Obsessive passion is characterized by an internal pressure that pushes the person to engage in the passionate activity, whereas harmonious passion is characterized by the person's choice to engage in the activity. The goal of the present study was to examine the outcomes of these types of passion toward gambling. A total of 554 participants completed instruments assessing their passion toward gambling, as well as several cognitive and affective outcomes. Results indicated that, in general, harmonious passion was associated with positive outcomes, while obsessive passion was related to negative consequences. Results also showed that casino activities accentuated both positive and negative outcomes by fostering both types of passion toward the gambling activity. Conceptual and practical implications are discussed.
\end{abstract}

Gambling is a phenomenon that has increased greatly in popularity over the past decade (Loto-Québec, 1999). While some people report experiencing enjoyment and thrill when gambling (e.g., Dickerson \& Adcock, 1987; Spanier, 1987), others encounter high levels of anxiety (Anderson \& Brown, 1987). For most people, gambling is a source of harmless distraction. For others, however, it has led to important financial and personal losses.

Eadington (1987) and Downes, Davies, David, and Stone (1976) distinguished between occasional gamblers and heavy gamblers. While occasional gamblers engage in the activity mostly for entertainment, heavy gamblers engage

1Preparation of this article was facilitated through doctoral fellowships from the Social Sciences and Humanities Research Council of Canada (SSHRC) to the first and third author, a doctoral fellowship from the Université du Québec à Montréal (UQAM) to the third author, a doctoral fellowship from the Fonds pour la Formation de Chercheurs et l'Aide à la Recherche (FCAR) to the fourth author, and through grants from SSHRC and Loto-Québec to the second author.

${ }^{2}$ Correspondence concerning this article should be addressed to Robert J. Vallerand, Laboratoire de Recherche sur le Comportement Social, Département de Psychologie, Université du Québec à Montréal, C.P. 8888, Station "Centre-Ville," Montréal, QC H3C 3P8, Canada. E-mail: vallerand .robert_J@uqam.ca

\section{0}

Journal of Applied Social Psychology, 2005, 35, 1, pp. 100-118.

Copyright $\subset 2005$ by V. H. Winston \& Son, Inc. All rights reserved. 
in gambling as a source of wealth and are committed to winning. While both types of gamblers might report experiencing strong feelings toward gambling, outcomes associated with each type of gambling involvement differ drastically. Different ways of becoming involved in an activity hence seem to influence greatly how this activity will be experienced.

Vallerand et al. (2003) proposed a conceptualization of passion that can shed light on the psychological mechanisms underlying activity involvement in general, and gambling involvement in particular. Vallerand et al.'s motivational perspective distinguished two types of passion: obsessive passion and harmonious passion. Both types of passion refer to a strong inclination toward an activity that one finds important, invests time in, and likes. However, important theoretical distinctions characterize the two types of passion. Obsessive passion is depicted by an internal pressure, which pushes individuals to engage in their passionate activity. This type of passion is likely to lead to conflicts between individuals' different life domains because they feel a strong sense of obligation to do the activity. Feeling compelled to engage in the activity, people are likely to neglect other areas of their life. Obsessive passion is hypothesized to lead to negative outcomes during and after activity engagement.

In contrast, harmonious passion is characterized by the person's choice to engage in the activity. The activity is said to be in harmony with the person's different life domains. Because people freely engage in their passionate activity, time and resources can be managed to accommodate every aspect of their lives. This type of passion is hypothesized to lead to positive outcomes during and after activity engagement.

Both obsessive passion and harmonious passion pertain to activities that acquire such importance for the person that they are internalized within the person's identity. However, motivational research has shown that regulations concerning noninteresting activities may be internalized in a controlled or an autonomous fashion in the person's identity (Sheldon, 2002), leading to diametrical consequences (Deci \& Ryan, 1985a, 1985b, 2000; Vallerand, 1997).

Vallerand et al. (2003) proposed that these divergent internalization processes also determine the type of passion that will be experienced toward the activity. Obsessive passion is hypothesized to result from a controlled internalization of the activity into the person's identity. A controlled internalization occurs when a person greatly enjoys and values his or her activity but various contingencies are attached to the activity such that the person feels an internal pressure to perform his or her activity. These contingencies are multi-determined and can take different forms. The activity may be tied to one or many aspects of the self, such as a feeling of social acceptance or a sense of self-worth. For instance, a person might believe strongly that being wealthy is the only avenue to gain social acceptance and love from his or her social network. Furthermore, this person might believe that gambling is the most likely way to become prosperous. In such a case, 
devoting oneself to gambling would no longer be a choice, but would be dictated by the desire to be accepted. The activity is thus tied to contingencies that lead people to engage in their activity without volitionally choosing to do so. Although people like their activity, they also feel compelled to engage in it. The passion must run its course as it controls the person. The activity takes disproportionate space in the person's identity as a result of its important associative network with other aspects of the self. The activity eventually causes conflicts with other activities in the person's life because activity engagement is out of the person's control, leading one to neglect other life domains (Vallerand et al., 2003).

Conversely, harmonious passion results from an autonomous internalization of the activity into the person's identity. Autonomous internalization occurs when a person greatly enjoys the activity and freely accepts the activity as important for him or her. In such a case, no contingency with other aspects of the self is attached to the activity, leaving people free to choose willingly to engage or not in the activity. Activity engagement is personally endorsed and remains under the person's willful control. The activity occupies a significant, but not overpowering, space in the person's identity and is in harmony with other aspects of the person's life (Vallerand et al., 2003).

Vallerand et al.'s (2003) perspective on passion sheds light on the contrasting outcomes people experience from activity involvement. Whereas some people experience positive consequences when engaged in their activity, a few others become so involved in their activity that they suffer negative outcomes. Previous research using the Passion scale (Vallerand et al., 2003) has shown that the two types of passion are indeed associated with diametrical consequences. People who develop an obsessive passion toward an activity tend to experience negative outcomes during activity engagement, such as perceived stress (Blanchard, 1999), reduced work satisfaction (Houlfort, Vallerand, \& Blanchard, 1999), depression (Rousseau, Vallerand, LeMartret, \& Clark, 1999), interpersonal conflicts (Séguin-Lévesque, Laliberté, Pelletier, Blanchard, \& Vallerand, 2003), and negative emotions after and when prevented from engaging in the passionate activity (Vallerand et al., 2003). In contrast, harmonious passion has been associated with emotional control (Blanchard, 1999), enhanced subjective well-being (Houlfort et al., 1999; Rousseau, Vallerand, \& Dumais, 2002), meaning in life and vitality (Rousseau et al., 1999), reduced stress (Blanchard, 1999), and positive emotions during and after engagement in the passionate activity (Vallerand \& Blanchard, 1999; Vallerand et al., 2003). This general pattern of results was found in settings as varied as sport (Mageau, Demers, Vallerand, \& Provencher, 2000; Rousseau, Vallerand, \& Dumais, 2002), work (Houlfort et al., 1999), and aging (Rousseau et al., 1999; Rousseau \& Vallerand, 2001).

Vallerand et al.'s (2003) conceptualization of passion recently has been applied successfully to gambling (Rousseau, Vallerand, Ratelle, Mageau, \& Provencher, 2002). Rousseau, Vallerand, Ratelle, et al. (2002) tested the validity of the concept of passion in the context of gambling activities and adapted the 
Passion scale to this new setting. The Gambling Passion scale showed satisfactory psychometric properties. Exploratory and confirmatory factor analyses indicated that the two types of passion could be distinguished clearly in this new setting. Both subscales were reliable (obsessive passion, $\alpha=.90$; harmonious passion, $\alpha=.76$ ), stable over a 1-month interval (obsessive passion, $r=.83, p<$ .001 ; harmonious passion, $r=.82, p<.001$ ), and demonstrated adequate validity. The two subscales of the Gambling Passion scale correlated as expected with measures of gambling involvement. Specifically, partial correlations (controlling for the other passion subscale) revealed that the more people reported having an obsessive passion toward gambling, the more they (a) gambled in general, (b) perceived themselves as being heavy gamblers, (c) gambled for longer periods of time, (d) gambled at more different types of games, and (e) gambled greater amounts of money. Harmonious passion did not predict these behaviors. Furthermore, although both types of passion were positively associated with game frequency and the perception of the game as part of oneself, obsessive passion was related more strongly to these two constructs than was harmonious passion. Taken together, these results support the validity of the conceptualization of passion, with obsessive passion being more strongly associated with heavy gambling than harmonious passion.

The present study has two main objectives. The first is to investigate whether the affective and cognitive experiences of gamblers during and after their involvement in their favorite gambling activity could result from their passion toward gambling. In line with previous findings (Vallerand et al., 2003), it is predicted that the two types of passion will lead to very different affective and cognitive outcomes. While obsessive passion toward gambling should lead to negative outcomes during and after activity engagement, harmonious passion should foster positive consequences during and after activity engagement. The second objective is to examine whether different gambling activities could have an impact on the subjective experience of gamblers through their impact on passion. It might be that some activities are more prone than others to generate passion toward gambling, which, in turn, would amplify the affective and cognitive outcomes of gambling. For example, Goffman (1967) and Oldman (1978) underscored the importance of the social dimension of casino activities as one determinant of long-term gambling involvement. Because of this social component, it is hypothesized that casino activities (relative to lotteries) will foster both types of passion, which, in turn, will engender different affective and cognitive outcomes.

Method

\section{Participants}

A total of 627 adults engaging in gambling activities (i.e., casino activities, lotteries) participated in the study. Of these 627 participants, 73 were excluded 
from the analyses because of missing values or unusable questionnaires. The remaining 554 participants (278 female, 273 male, 3 gender not specified) had a mean age of 48.2 years. The average annual income per participant was between $\$ 30,000$ and $\$ 39,999$ (Canadian). ${ }^{3}$

\section{Procedure}

Participants were recruited at the Montréal's Casino $(n=487)$ and in shopping centers $(n=67)$, where they were asked to complete a questionnaire. Questionnaires were filled out anywhere between 9 a.m. and midnight, although most participants $(60 \%)$ responded between noon and 6 p.m. To ensure participants' anonymity at the casino, a secluded area was prepared near the interior parking lot where participants could complete the questionnaire confidentially.

\section{Measures}

Two different versions of the questionnaire were constructed. Both versions included the Gambling Passion scale (Rousseau, Vallerand, Ratelle, et al., 2002), which assesses the two types of passion, as well as measures of different affective and cognitive outcomes of these types of passion. The two versions of the questionnaire differed with respect to which affective and cognitive outcomes were assessed. Participants were asked to complete only one version of the questionnaire. Consequently, the number of participants varies across analyses. This procedure allowed us to assess a greater range of outcomes without requesting excessive effort from participants.

Participants first completed the Gambling Passion scale (Rousseau, Vallerand, Ratelle, et al., 2002). This 10-item scale assesses the two types of passion: harmonious passion and obsessive passion. Participants rated on a 7point Likert-type scale the extent to which they agreed with each statement regarding their favorite gambling game. The answer scale ranged from 1 (do not agree at all) to 7 (very strongly agree). A sample item from the obsessive passion subscale is "I have a tough time controlling my need to gamble at this game," while "Gambling is in harmony with the other activities in my life" is an item measuring harmonious passion. As already mentioned, previous findings supported the scale's reliability, construct validity, temporal stability, as well as its factor structure (Rousseau, Vallerand, Ratelle, et al., 2002). In the present study, both subscales had satisfactory reliability coefficients (harmonious passion, Cronbach's $\alpha=.81$; obsessive passion, $\alpha=.90$ ).

${ }^{3}$ As one should expect from a randomly selected sample of gamblers, only a minority of participants could be classified as truly passionate toward gambling. Specifically, $16 \%$ of the total sample scored above the midpoint on all three aforementioned criteria of passion (i.e., an activity that one likes, finds important, and invests time in). Nevertheless, analyses performed on this smaller sample of passionate gamblers showed that the pattern of results remained the same as with the total sample. 
The second part of the questionnaire assessed two different types of outcomes. For each instrument, participants indicated their level of agreement with the scales' items on a Likert-type scale identical to the one described for the Passion scale. The first set of outcomes concerned feelings and thoughts experienced during participants' engagement in their favorite gambling activity. With the stem "Usually, while I play at my favorite game . .." we assessed feelings of amusement and fun (3 items; e.g., ". . I I have fun"; $\alpha=.84$ ), perceptions of challenge (2 items; e.g., ". . . my abilities allow me to face the challenges of the game"; $\alpha=$ .67 ), concentration (2 items; e.g., ". . . my attention is totally devoted to what I am doing"; $\alpha=.74$ ), perceptions of control (3 items, e.g., ". . . I feel totally in control of what I am doing"; $\alpha=.63$ ), feelings of being judged by others (3 items; e.g., ". . I I am not bothered by what other people think of me"; $\alpha=.75)$, feelings of guilt (3 items; e.g., ". . . I feel guilty to play"; $\alpha=.79$ ), anxiety (3 items; e.g., ". . . I feel tense"; $\alpha=.84$ ), thoughts about winning ( 3 items; e.g., ". . I I am sure that I can win"; $\alpha=.61$ ), as well as positive (2 items; e.g., ". . . I feel cheerful”; $\alpha=.64$ ) and negative emotions ( 2 items; e.g., “. . . I feel unhappy”; $\alpha=.57$ ). Table 1 presents the means and standard deviations of each scale.

The second set of outcomes pertained to feelings and thoughts experienced after participants' engagement in their favorite gambling activity. With the stem "Usually, right after playing at my favorite game ..." we assessed feelings of guilt (4 items; e.g., “. . . I feel guilty for having played”; $\alpha=.80$ ), vitality (Ryan \& Frederick, 1997; 2 items; e.g., “. . . I feel a lack of energy” [recoded]; $\alpha=.56$ ), anxiety (3 items; e.g., ". . . I feel tense"; $\alpha=.87$ ), as well as positive ( 2 items; e.g., ". . . I feel cheerful”; $\alpha=.84$ ) and negative emotions (2 items; e.g., “. . I feel unhappy"; $\alpha=.71$ ) after having engaged in the activity. Table 2 presents the means and standard deviations of each scale.

\section{Results}

Three sets of analyses were conducted to meet the present study's objectives. First, partial correlations were performed to assess relationships between various outcomes and harmonious passion and obsessive passion toward gambling. Second, MANOVAs were conducted to test for differences in passion and affective and cognitive outcomes as a function of gender and gambling activities. Third, regression analyses were performed to evaluate the relationship between types of gambling activities and affective and cognitive outcomes as mediated by the two types of passion.

\section{Consequences of Passion Toward Gambling Activities}

Prior to all analyses, variables were scrutinized for univariate normality. Overall, univariate values of kurtosis and skewness were generally adequate, with most values ranging from -1.0 to +1.0 and a mean skewness of .51 and a 
Table 1

Partial Correlations Between Outcome Variables During Engagement in Gambling Activities and One Type of Passion While Controlling for the Other

\begin{tabular}{ccccccc}
\hline $\begin{array}{c}\text { Outcomes during } \\
\text { engagement in gambling } \\
\text { activities }\end{array}$ & $M$ & $S D$ & \multicolumn{2}{c}{$\begin{array}{c}\text { Obsessive } \\
\text { passion }\end{array}$} & & \multicolumn{2}{c}{$\begin{array}{c}\text { Harmonious } \\
\text { passion }\end{array}$} \\
\cline { 5 - 7 } & & & $p r$ & & $r$ & $p r$ \\
\hline
\end{tabular}

Feelings of amusement and fun

(Versions A and B, $n=552) \quad 5.05 \quad 1.58 \quad-.18^{* * *} \quad .04(n s) \quad .45 * * * \quad .42 * * *$

Perceptions of challenge

(Version A, $n=269$ )

$\begin{array}{llllll}3.15 & 1.64 & .06(n s) & .31 * * * & .55^{* * *} & .61 * * *\end{array}$

Positive emotions

(Version A, $n=275$ )

$\begin{array}{llllll}4.52 & 1.61 & -.16^{* *} & .15^{* *} & .58^{* * *} & .57 * * *\end{array}$

Concentration

(Version A, $n=265$ )

$\begin{array}{llllll}4.21 & 1.78 & .16^{* *} & .28^{* * *} & .25^{* * *} & .34 * * *\end{array}$

Perceptions of control

(Version A, $n=273$ )

$\begin{array}{llllll}4.24 & 1.62 & -.22 * * * & -.16(n s) & .18 * * & .10(n s)\end{array}$

Feelings of being judged by others

(Version A, $n=278$ )

3.85

$1.77 .08(n s)-.12 *$

$-.38 * * *-.38 * * *$

Feelings of guilt

(Version A, $n=272$ )

$\begin{array}{llllll}2.13 & 1.44 & .64 * * * & .61 * * * & -.19 * * & .14 *\end{array}$

Negative emotions

(Version A, $n=264$ )

$2.14 \quad 1.41 \quad .36 * * * \quad .39 * * * \quad-.00(n s) \quad .17 * *$

Anxiety

(Version A, $n=273$ )

$\begin{array}{llllll}2.82 & 1.66 & .52 * * * & .58 * * * & .11(n s) & .34 * * *\end{array}$

Thoughts of winning

$\begin{array}{lllllll}(\text { Versions } \mathrm{A} \text { and } \mathrm{B}, n=550) & 2.91 & 1.36 & .43 * * * & .54 * * * & .24 * * * & .43 * * *\end{array}$

${ }^{*} p<.05 .{ }^{*} p<.01 . * * * p<.001$.

mean kurtosis of .23 (Muthén \& Kaplan, 1985). Given the large number of statistical tests performed throughout the present paper (at least 50), the critical $p$ value was set to .001 to prevent inflation of the probability of Type I errors. Consequently, all analyses significant at a $p$ value of .01 are described as marginally significant. 


\section{Table 2}

Partial Correlations Between Outcome Variables After Engagement in Gambling Activities and One Type of Passion While Controlling for the Other

\begin{tabular}{|c|c|c|c|c|c|c|}
\hline \multirow{2}{*}{$\begin{array}{c}\text { Outcomes after } \\
\text { engagement in gambling } \\
\text { activities }\end{array}$} & \multirow[b]{2}{*}{$M$} & \multirow[b]{2}{*}{$S D$} & \multicolumn{2}{|c|}{$\begin{array}{l}\text { Obsessive } \\
\text { passion }\end{array}$} & \multicolumn{2}{|c|}{$\begin{array}{l}\text { Harmonious } \\
\text { passion }\end{array}$} \\
\hline & & & $r$ & $p r$ & $r$ & $p r$ \\
\hline $\begin{array}{l}\text { Positive emotions } \\
\text { (Version } \mathrm{B}, n=271 \text { ) }\end{array}$ & 4.19 & 1.62 & $-.11(n s)$ & $.16^{* *}$ & $.52 * * *$ & $.52 * * *$ \\
\hline $\begin{array}{l}\text { Vitality } \\
(\text { Version } \mathrm{B}, n=271)\end{array}$ & 5.32 & 1.45 & $-.32 * * *$ & $-.37 * * *$ & $-.07(n s)$ & $-.24 * * *$ \\
\hline $\begin{array}{l}\text { Anxiety } \\
(\text { Version A, } n=272)\end{array}$ & 2.26 & 1.56 & $.55 * * *$ & $.57 * * *$ & $-.02(n s)$ & $.25 * * *$ \\
\hline $\begin{array}{l}\text { Feelings of guilt } \\
\text { (Version A, } n=273 \text { ) }\end{array}$ & 2.16 & 1.35 & $.60 * * *$ & $.60 * * *$ & $-.11(n s)$ & $.19 * * *$ \\
\hline $\begin{array}{l}\text { Negative emotions } \\
\text { (Version } \mathrm{B}, n=272 \text { ) }\end{array}$ & 2.23 & 1.38 & $.38 * * *$ & $.37 * * *$ & $-.07(n s)$ & $.12(n s)$ \\
\hline
\end{tabular}

$* * p<.01 . * * * p<.001$.

In the first set of analyses, partial correlations were conducted to evaluate relationships between harmonious passion and obsessive passion and the various consequences. Partial correlations were chosen because they enabled us to remove statistically the common variance between the two types of passion, and thus assess the relationships between one type of passion and the outcome variables independently from the other type of passion. The two types of passion were expected to be correlated positively, because as types of passion they share common elements. Indeed, both types of passion refer to a special relationship with an activity that a person has internalized in his or her identity. In both cases, the person likes his or her activity, finds it important, and devotes time to it. In line with previous research on passion (Vallerand et al., 2003), the correlation between harmonious passion and obsessive passion was .44. Results pertaining to the outcome variables during engagement in gambling activities are presented first, followed by results regarding outcome variables after engagement in gambling activities.

Outcomes during engagement in gambling activities. Partial correlations reveal that harmonious passion was related to several positive outcomes during 
engagement in gambling activities. Specifically, harmonious passion manifested strong positive relationships with feelings of amusement and fun $(p r=.45, p<$ $.001)$, perceptions of challenge $(p r=.55, p<.001)$, and positive emotions $(p r=$ $.58, p<.001)$. Harmonious passion was also positively related, but to a lesser extent, to concentration $(p r=.25, p<.001)$ and having thoughts of winning ( $p r=$ $.24, p<.001)$, and only marginally to perceptions of control $(p r=.18, p<.01)$. Harmonious passion was negatively related to negative outcomes such as feelings of being judged by others $(p r=-.38, p<.001)$. A marginal negative relationship also was observed between harmonious passion and feelings of guilt ( $p r=$ $-.19, p<.01$ ). Finally, harmonious passion was not related significantly to negative emotions or anxiety. Table 1 presents the results of the partial correlations along with the Pearson correlations.

A reverse pattern of results was found for obsessive passion. Obsessive passion showed strong positive relationships with several negative outcomes during engagement in gambling activities, such as feelings of guilt $(p r=.64, p<.001)$, anxiety $(p r=.52, p<.001)$, and negative emotions $(p r=.36, p<.001)$. Obsessive passion was also positively correlated with having thoughts of winning ( $p r=$ $.43, p<.001)$. Conversely, obsessive passion was negatively related to positive outcomes, such as perceptions of control $(p r=-.22, p<.001)$ and feelings of amusement and fun $(p r=-.18, p<.001)$. Obsessive passion also had a marginal negative relationship with positive emotions $(p r=-.16, p<.01)$, but a marginal positive relationship with concentration $(p r=.16, p<.01)$. Finally, obsessive passion was unrelated to perceptions of challenge and feelings of being judged by others. These results are presented in Table 1 along with results from Pearson correlations.

It should be noted that while harmonious passion was generally positively related to positive outcomes and obsessive passion was generally positively associated to negative outcomes, both harmonious passion and obsessive passion were positively and significantly related to having thoughts of winning. However, the relationship between having thoughts of winning and obsessive passion ( $p r=.43, p<.001)$ was stronger than between thoughts of winning and harmonious passion $(p r=.24, p<.001)$. This difference also reflected in the correlation coefficients was tested for statistical significance using the test for the equality of two dependent correlations proposed by Williams (1959) and recommended by Steiger (1980). The correlation between having thoughts of winning and obsessive passion $(r=.54)$ was marginally stronger than that with harmonious passion $(r=.42), t(505)=2.84, p<.01$.

Outcomes after engagement in gambling activities. Harmonious passion and obsessive passion also differed in their relationships with outcomes experienced after participants' engagement in gambling activities. After controlling for the influence of obsessive passion, harmonious passion was related positively to positive emotions $(p r=.52, p<.001)$. Contrary to expectations, harmonious passion 


\section{Table 3}

Means and Standard Deviations of Harmonious Passion and Obsessive Passion According to Gender and Gambling Activity

\begin{tabular}{lccccc}
\hline & \multicolumn{2}{c}{ Obsessive passion } & & \multicolumn{2}{c}{ Harmonious passion } \\
\cline { 2 - 3 } \cline { 5 - 6 } & $M$ & $S D$ & & $M$ & $S D$ \\
\hline Gender & & & & & \\
Women $(n=278)$ & 2.23 & 1.45 & & 2.84 & 1.37 \\
Men $(n=273)$ & 2.45 & 1.55 & & 3.20 & 1.38 \\
Gambling activity & & & & & \\
Lottery tickets $(n=220)$ & 1.90 & 1.21 & & 2.54 & 1.37 \\
Casino activities $(n=334)$ & 2.64 & 1.61 & & 3.34 & 1.31 \\
\hline
\end{tabular}

was not related positively to vitality. Furthermore, harmonious passion was not related negatively to negative outcomes such as anxiety, guilt, or negative emotions. Conversely, obsessive passion was related positively to negative outcomes such as feelings of guilt $(p r=.60, p<.001)$, anxiety $(p r=.55, p<.001)$, and negative emotions ( $p r=.38, p<.001)$, but negatively associated with vitality ( $p r=$ $-.32, p<.001)$. Finally, obsessive passion was unrelated to positive emotions. These results are presented in Table 2 .

\section{Differences in Passion as a Function of Gender and Gambling Activities}

A two-factor MANOVA assessed the influence of gender and type of gambling activities (i.e., casino vs. lottery tickets) on the two types of passion. Results first showed that there was no interaction between gender and type of gambling activities (Wilks's $\Lambda=.99$ ), exact $F(2,500)=1.50, p=.22$. Second, results showed a nonsignificant multivariate main effect for gender (Wilks's $\Lambda=$ $.99)$, exact $F(2,500)=2.64, p=.07$. Third, a significant main effect was found for the type of gambling activities in which participants engaged (Wilks's $\Lambda=$ $.91)$, exact $F(2,500)=24.34, p<.001$. Subsequent ANOVAs revealed that, on average, participants engaging in casino activities experienced higher levels of obsessive passion and harmonious passion than did participants playing the lottery: obsessive passion, $F(1,501)=31.51, p<.001$; harmonious passion, $F(1,501)=37.15, p<.001$. Table 3 presents the means and standard deviations for harmonious passion and obsessive passion as a function of type of activity and gender. 


\section{Differences in Affective and Cognitive Outcomes as a Function of Gender and Gambling Activities}

A total of three 2-factor MANOVAs were conducted: The first MANOVA was performed on outcomes measured in Version A; the second was performed on consequences assessed in Version B; and the last one was performed on two outcomes measured in both versions of the questionnaire (i.e., thoughts of winning, feelings of amusement and fun). Results first showed that there was no significant interaction between gender and type of activity across analyses (all $p$ s $>.001)$. Second, all three main effects involving gender were nonsignificant (all $p \mathrm{~s}>.001$ ). Finally, significant differences were found with the affective and cognitive outcomes as a function of type of gambling activity: MANOVA 1 , Wilks's $\Lambda=.87$, exact $F(6,246)=5.92, p<.001 ;$ MANOVA $_{2}$, Wilks's $\Lambda=.94$, exact $F(2,541)=16.59, p<.001$; and $\mathrm{MANOVA}_{3}$, Wilks's $\Lambda=.87$, exact $F(7$, 233) $=5.13, p<.001$.

Specifically, subsequent ANOVAs reveal that, in general, people experienced stronger affective and cognitive outcomes following engagement in casino activities compared to lotteries, although some differences did not meet statistical significance (Table 4). One exception was found where people experienced significantly more vitality after playing the lottery than after engaging in casino activities. Thus, the results generally show that gamblers who engaged in casino activities reported higher levels of positive and negative outcomes than did gamblers playing the lottery, indicating that casino activities seem to amplify gambling outcomes (both positive and negative). Means, standard deviations, and significance tests are presented in Table 4.

\section{Passion as a Mediator of the Impact of Type of Gambling Activity on Affective and Cognitive Outcomes}

It was hypothesized that differences in the outcomes experienced in the two types of gambling activity would be mediated by differences in the two types of passion fostered by these different gambling activities. Compared to lotteries, casino activities might be more favorable to the development of both harmonious passion and obsessive passion toward gambling, which, in turn, might lead to amplified positive and negative outcomes. As recommended by Baron and Kenny (1986), when testing mediator effects, direct relationships between the two types of gambling activity and the various outcomes were first assessed using multiple regression analyses. Following Cohen and Cohen's (1983) procedure, the two types of gambling activity were dummy-coded to create a dichotomous variable that represents group membership. According to this procedure, each person in each group is coded by an arbitrary number representing group membership. In the present case, participants who engaged in casino 
Table 4

Differences on Affective and Cognitive Outcomes as a Function of the Two Types of Gambling Activity

\begin{tabular}{|c|c|}
\hline $\begin{array}{c}\text { Casino } \\
\text { activities }\end{array}$ & $\begin{array}{l}\text { Lottery } \\
\text { tickets }\end{array}$ \\
\hline$M \quad S D$ & $M \quad S D$ \\
\hline
\end{tabular}

Outcomes during engagement in gambling activities

Feelings of amusement and fun

$5.29 \quad 1.43$

4.68

$1.72 F(1,542)=22.34 * * *$

Perceptions of challenge

$3.39 \quad 1.52$

2.79

$1.77 F(1,239)=4.15^{*}$

Positive emotions

$4.84 \quad 1.43$

4.04

1.74

$F(1,239)=17.75 * * *$

Concentration

$4.35 \quad 1.60$

4.00

$2.02 F(1,251)=2.61, n s$

Perceptions of control

$4.19 \quad 1.55$

4.32

$1.72 F(1,251)=0.05, n s$

Feelings of being judged by others

3.73

Feelings of guilt

$2.38 \quad 1.56$

1.74

$1.13 F(1,251)=17.29 * * *$

Negative emotions

$2.34 \quad 1.53$

1.83

$1.13 F(1,239)=5.07 *$

Anxiety

$3.24 \quad 1.70$

2.17

$1.36 F(1,251)=29.88 * * *$

Thoughts of winning

$3.08 \quad 1.33$

2.65

$1.37 F(1,542)=13.49 * * *$

Outcomes after engagement in gambling activities

$\begin{array}{llllll}\text { Positive emotions } & 4.43 & 1.43 & 3.83 & 1.81 & F(1,239)=9.47 * * \\ \text { Vitality } & 5.03 & 1.48 & 5.74 & 1.31 & F(1,239)=15.64 * * * \\ \text { Anxiety } & 2.64 & 1.74 & 1.68 & 0.98 & F(1,251)=26.95 * * * \\ \text { Feelings of guilt } & 2.46 & 1.51 & 1.72 & 0.90 & F(1,251)=21.80^{* * *} \\ \text { Negative emotions } & 2.42 & 1.50 & 1.96 & 1.14 & F(1,239)=6.80^{* *}\end{array}$

${ }^{*} p<.05 .{ }^{* *} p<.01 .{ }^{* * *} p<.001$.

activities were coded as 2, and participants who played lotteries were coded as 1 . Direct relationships between types of gambling activity and the various outcomes prior to the inclusion of any mediator variables were labeled direct effects and are presented in Table 5 for each cognitive and affective outcome. The overall pattern of positive beta weights indicates that casino activities generated more positive and negative outcomes than did playing the lottery.

In a second step, direct paths between types of gambling activity and cognitive and affective outcomes were assessed while including the two passions as 
Table 5

Comparison of Standardized Beta Weights for Direct Models and Mediator Models Where Harmonious Passion and Obsessive Passion Mediate the Impact of Types of Gambling Activity on Various Outcomes

\begin{tabular}{cccc}
\multicolumn{4}{c}{ Standardized $\beta$} \\
\hline $\begin{array}{c}\text { Mirect } \\
\text { model }\end{array}$ & Path a & Path b & Path c \\
\hline Direct & $\begin{array}{c}\text { Residual } \\
\text { direct } \\
\text { effect }\end{array}$ & $\begin{array}{c}\text { Obsessive } \\
\text { effect }\end{array}$ & $\begin{array}{c}\text { Harmo- } \\
\text { nious } \\
\text { passion }\end{array}$
\end{tabular}

Outcomes during engagement in gambling activities

$\begin{array}{lllll}\text { Feelings of amusement and fun } & .19^{* * *} & .11^{* *} & -.19^{* * *} & .47^{* * *} \\ \text { Perceptions of challenge } & .18^{* *} & -.04(n s) & .06(n s) & .60^{* * *} \\ \text { Positive emotions } & .24 * * * & .06(n s) & -.13^{*} & .61^{* * *} \\ \text { Concentration } & .10(n s) & .01(n s) & .16^{*} & .26^{* * *} \\ \text { Perceptions of control } & -.04(n s) & -.05(n s) & -.27 * * * & .24 * * * \\ \text { Feelings of being judged by } & & & & \\ \quad \text { others } & -.08(n s) & .04(n s) & .06(n s) & -.42^{* * *} \\ \text { Feelings of guilt } & .22^{* * *} & .12^{* *} & .71^{* * *} & -.20^{* * *} \\ \text { Negative emotions } & .18^{* *} & .06(n s) & .40^{* * *} & -.01(n s) \\ \text { Anxiety } & .32^{* * *} & .20^{* * *} & .52^{* * *} & .06(n s) \\ \text { Thoughts of winning } & .16^{* * *} & -.01(n s) & .44^{* * *} & .22^{* * *}\end{array}$

Outcomes after engagement in gambling activities

$\begin{array}{lcccc}\text { Positive emotions } & .18^{* *} & .03(n s) & -.09(n s) & .56 * * * \\ \text { Vitality } & -.24 * * * & -.12 * & -.34 * * * & -.04(n s) \\ \text { Anxiety } & .30^{* * *} & .20^{* * *} & .58 * * * & -.09(n s) \\ \text { Feelings of guilt } & .27 * * * & .18^{* * *} & .64 * * * & -.15^{* *} \\ \text { Negative emotions } & .17 * * & .10(n s) & .41^{* * *} & -.08(n s)\end{array}$

${ }^{*} p<.05 . * * p<.01 . * * * p<.001$.

mediators for relationships between types of gambling activity and cognitive and affective outcomes (Figure 1). This second set of direct paths (labeled Paths $a$ in Figure 1) represents the relationships between gambling activities and 


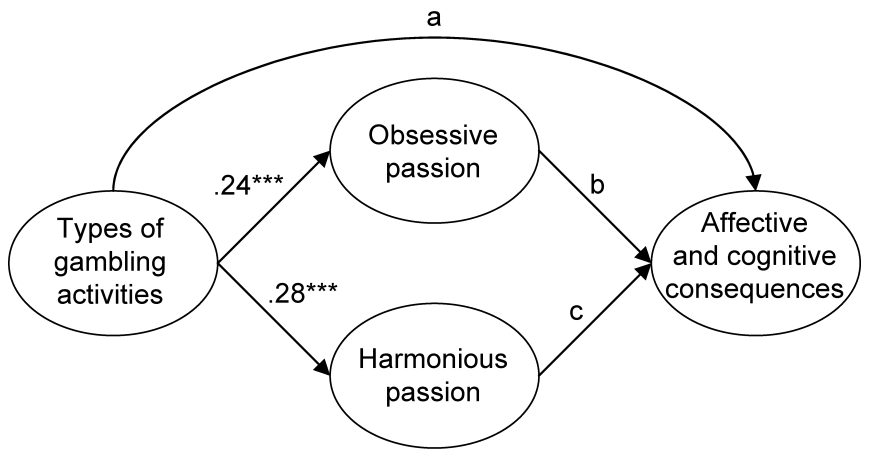

Figure 1. Mediator model where harmonious passion and obsessive passion mediate the impact of types of gambling activity on affective and cognitive outcomes.

cognitive and affective outcomes that could not be accounted for by the two passions. We then compared these residual direct paths (labeled $a$ in Figure 1) with the aforementioned original direct paths. If the two passions mediate the relationship between types of activity and cognitive and affective outcomes, residual direct paths (labeled $a$ in Figure 1) should be nonsignificant or lower than the original direct paths (Baron \& Kenny, 1986). To facilitate this comparison, Table 5 presents the residual direct paths (labeled $a$ in Figure 1) alongside the original direct paths for each individual outcome. Furthermore, for the two passions to be considered as mediators, paths from types of activities to passions and from passion to outcome variables should be significant (Baron \& Kenny, 1986).

Results first indicate that passion was related differentially to the two types of gambling activity. The more people participated in casino activities, the more they were inclined to report an obsessive passion $(\beta=.24, p<.001)$ as well as a harmonious $(\beta=.28, p<.001)$ passion toward gambling activities (Figure 1$)$. Second, the results reveal that the two passions mediated the relationship between types of gambling activity and cognitive and affective outcomes. Indeed, compared to the original direct paths, all residual direct paths (labeled $a$ in Figure 1) either became nonsignificant or were greatly reduced after the two passions were included as mediators (Table 5). Table 5 also presents the relationships between the two types of passion with the various outcomes (labeled $b$ and $c$, respectively). Finally, in all cases, Paths $\mathrm{b}$ and $\mathrm{c}$ were stronger than Paths a. In short, the results support the hypothesis that different types of gambling activity were related differentially to the two types of passion, with casino activities being associated with higher levels of passion toward gambling than lotteries. In turn, obsessive passion predicted negative consequences, while harmonious passion was related to positive consequences. 


\section{Discussion}

The present study had two main objectives. First, we investigated if the two types of passion (harmonious passion and obsessive passion) could account for the divergent affective and cognitive consequences of gambling during and after activity engagement. Second, we verified if the two types of passion mediated the relationship between activity type and the various outcomes. The results first show that the two types of passion were related to very different consequences during and after gambling engagement. Indeed, harmonious passion generally was associated with positive outcomes, such as feelings of amusement and fun, positive emotions, and perceptions of challenge and control, while negatively predicting feelings of guilt and of being judged by others. Obsessive passion displayed a reverse pattern of relationship with the outcomes. More specifically, obsessive passion was associated negatively with feelings of amusement and fun, positive emotions, perceptions of control, and vitality; while positively predicting feelings of guilt, negative emotions, and anxiety. The general pattern of partial correlations thus suggests that obsessive passion is an important predictor of negative outcomes, while harmonious passion seems to account for the positive consequences of gambling.

Furthermore, obsessive passion seems especially important to understand gamblers' affective and cognitive experiences after activity engagement. In line with Vallerand et al.'s (2003) conceptualization of passion, people with an obsessive passion might not take the time to consider whether or not they should engage in their activity of passion because they have not internalized their activity of passion in an autonomous fashion. They instead feel controlled by their activity. As the present results suggest, people with an obsessive passion may look back at their gambling engagement with anxiety, guilt, and negative emotions because their gambling engagement did not feel like a conscious choice, but rather as driven by their passion. Conversely, people with a harmonious passion experience gambling engagement as an activity under their control. Consequently, they tend not to experience negative emotions after activity engagement because gambling represents a consciously chosen activity. They thus seem to benefit from activity engagement through the experience of positive emotions after gambling.

Analyses of differences on passion and the various outcomes show that the type of gambling activity seemed to impact on gamblers' experience. Casino activities compared to lotteries seemed to amplify both positive and negative outcomes during and after gambling engagement. Such effects were found to be mediated by the two types of passion, with obsessive passion predicting worsened negative consequences, and harmonious passion being related to heightened positive consequences. Thus, although casino activities amplified positive and negative outcomes, the valence of the outcomes depended on the 
type of passion. These results underscore the importance of passion to understand the impact of casino activities on the affective and cognitive outcomes of gambling involvement.

It should be noted that casino activities were related to more anxiety and feelings of guilt during and after gambling engagement independent of the two types of passion. Other processes should thus be explored to explain the impact of casino activities on these outcomes. It might be that the negative social connotations associated with gambling are more relevant for casino activities than for lotteries, which would generate feelings of guilt. It is also possible that the stakes of casino activities are more important than lotteries, thus generating more anxiety.

Taken together, the present findings suggest that it is not engaging in gambling activities as such that is problematic, but rather having an obsessive passion toward the activity. Harmonious passion toward gambling was actually related to positive outcomes. The present results parallel previous findings obtained in other life domains (Vallerand et al., 2003). Vallerand et al.'s motivational perspective of passion was thus successfully generalized to gambling activities, confirming its usefulness as a general theoretical framework. This new perspective can shed light on the psychological processes that may underlie the different types of gambling involvement. While some people gamble regularly without serious consequences, others become pathological gamblers (Ladouceur \& Dubé, 1997; Walker, 1992).

The two types of passion as different types of activity involvement should help to understand and distinguish healthy gambling from pathological gambling. Obsessive passion was shown to predict important negative consequences in other life domains, and it also might account partly for pathological gambling and its tragic consequences (American Psychiatric Association, 1994). For example, in a recent study, Ratelle, Vallerand, Mageau, Rousseau, and Provencher (2004) reported evidence that obsessive passion was associated with problem gambling, as assessed by the revised South Oaks Gambling Screen (SOGS; Lesieur \& Blume, 1993). Harmonious passion, on the other hand, was not associated with such a negative outcome. Understanding the two types of passion in general should thus lead to a better comprehension of the processes underlying the different types of gambling involvement in particular.

From an applied perspective, future research should attempt to identify the determinants of the two types of passion in order to prevent obsessive passion toward gambling. Future research is needed to identify potential intrapersonal, interpersonal, and social determinants of the two types of passion. There might be an interplay of factors that make an activity singularly important for an individual. For example, people who seldom feel competent or accepted in their daily lives might cling to gambling as their only source of competence or self-worth. Moreover, characteristics inherent in an activity might also differentially foster passionate feelings in people. For instance, the structure inherent in gambling 
activities might affect passion experienced toward these activities. It might be that intermittent reinforcement schedules that characterize gambling in casino settings facilitate the development of passion by providing competence feedback to participants. Understanding the determinants of passion is especially important for gambling activities because of the devastating consequences of having an obsessive passion toward these activities (i.e., financial losses and negative emotions).

Several limits of the present study should be underscored. First, a correlational design was used with only one point in time. Causality, therefore, cannot be determined from the present design. Second, although an effort was made to analyze differences in types of activity (casino activities vs. lotteries), differences also might exist between other gambling activities, such as skill-oriented versus luck-oriented gambling activities (Chantal \& Vallerand, 1996). Unfortunately, the present study did not contain the required variables to test this hypothesis. Finally, gamblers were not assigned randomly to the different types of gambling activity. Thus, it is not clear whether casino activities (and perhaps casino settings) actually foster passionate feelings in gamblers or that they merely attract different (e.g., more passionate) gamblers than would lotteries.

Despite these methodological limitations, the present paper offers a general theoretical framework to study gambling involvement. From a theoretical perspective, it suggests that there are two distinct ways of becoming involved in an activity such as gambling and that these two types of passion lead to different affective and cognitive consequences. From an applied perspective, the present approach proposes that obsessive passion represents one of the psychological underpinnings of pathological gambling, thus leading to potentially important applications. Future research along these lines might prove fruitful from both a theoretical and an applied perspective.

\section{References}

American Psychiatric Association. (1994). Diagnostic and statistical manual of mental disorders (4th ed.). Washington, DC: Author.

Anderson, G., \& Brown, R. I. F. (1987). Some applications of reversal theory to the explanations of gambling and gambling addictions. Journal of Gambling Behavior, 3, 179-189.

Baron, R. M., \& Kenny, D. A. (1986). The moderator-mediator variable distinction in social psychological research: Conceptual, strategic, and statistical considerations. Journal of Personality and Social Psychology, 51, 1173-1182. Blanchard, C. M. (1999). Passion and physical health. Unpublished doctoral dissertation, Université du Québec à Montréal, Montréal, Canada.

Chantal, Y., \& Vallerand, R. J. (1996). Skill versus luck: A motivational analysis of gambling involvement. Journal of Gambling Studies, 12, 407-418. 
Cohen, J., \& Cohen, P. (1983). Applied multiple regression/correlation analysis for the behavioral sciences (2nd ed.). New Jersey: Lawrence Erlbaum.

Deci, E. L., \& Ryan, R. M. (1985b). Intrinsic motivation and self-determination in human behavior. New York, NY: Plenum.

Deci, E. L., \& Ryan, R. M. (2000). The "what" and "why" of goal pursuits: Human needs and the self-determination of behavior. Psychological Inquiry, 11, 227-268.

Dickerson, M. G., \& Adcock, S. (1987). Mood, arousal, and cognitions in persistent gambling: Preliminary investigation of a theoretical model. Journal of Gambling Behavior, 3, 3-15.

Downes, D. M., Davies, B. P., David, M. E., \& Stone, P. (1976). Gambling, work, and leisure: A study across three areas. London, UK: Routledge and Kegan Paul.

Eadington, W. R. (1987). Economic perceptions of gambling behavior. Journal of Gambling Behavior, 3, 264-273.

Goffman, E. (1967). Interaction ritual. Garden City, NJ: Doubleday.

Houlfort, N., Vallerand, R. J., \& Blanchard, C. M. (1999, October). Passion au travail et ajustement psychologique: Une étude prospective [Passion toward work and psychological adjustement: A prospective study]. Paper presented at the 22nd annual Congress of the Québec Society for Research in Psychology, Québec, Canada.

Ladouceur, R., \& Dubé, D. (1997). Monetary incentive and erroneous perceptions in American roulette. Psychology: A Journal of Human Behavior, 34, 27-32.

Lesieur, H. R., \& Blume, S. B. (1993). Revising the South Oaks Gambling Screen in different settings. Journal of Gambling Studies, 9, 213-223.

Loto-Québec. (1999). Rapport annuel 1998-1999 [1998-1999 annual report]. Montréal, Canada: The Directorate of Public Affairs.

Mageau, G. A., Demers, M.-A., Vallerand, R. J., \& Provencher, P. (2000, October). L'impact de la passion sur les stratégies de coping et l'anxiété d'état [The impact of passion on coping strategies and state anxiety]. Paper presented at the 23rd annual Congress of the Québec Society for Research in Psychology, Hull, Canada.

Muthén, B., \& Kaplan, D. (1985). A comparison of methodologies for the factor analysis of non-normal Likert variables. British Journal of Mathematical and Statistical Psychology, 38, 171-189.

Oldman, D. J. (1978). Compulsive gamblers. Sociological Review, 26, 349-371.

Ratelle, C. F., Vallerand, R. J., Mageau, G. A., Rousseau, F. L., \& Provencher, P. J. (2004). When passion leads to pathology: A look at gambling. Journal of Gambling Studies, 20, 105-119.

Rousseau, F. L., \& Vallerand, R. J. (2001, July). A longitudinal study of the relationships among passionate activities, affect, and psychological adjustment 
among seniors. Paper presented at the 17th World Congress of the International Association of Gerontology, Vancouver, Canada.

Rousseau, F. L., Vallerand, R. J., \& Dumais, A. (2002). When an activity is more than fun: A look at passion for sport. Manuscript in preparation, Université du Québec à Montréal, Montréal, Canada.

Rousseau, F. L., Vallerand, R. J., LeMartret, K., \& Clark, M. (1999, November). Passion and subjective well-being among nursing home residents. Paper presented at the 28th annual Scientific and Educational Meeting of the Canadian Association on Gerontology, Ottawa, Canada.

Rousseau, F. L., Vallerand, R. J., Ratelle, C. F., Mageau, G. A., \& Provencher, P. J. (2002). Passion and gambling: On the validation of the Gambling Passion Scale (GPS). Journal of Gambling Studies, 18, 45-66.

Ryan, R. M., \& Frederick, C. (1997). On energy, personality, and health: Subjective vitality as a dynamic reflection of well-being. Journal of Personality, 65, 529-565.

Séguin-Lévesque, C., Laliberté, M.-L. N., Pelletier, L. G., Blanchard, C., \& Vallerand, R. J. (2003). Harmonious and obsessive passion for the Internet: Their associations with the couples' relationships. Journal of Applied Social Psychology, 33, 197-221.

Sheldon, K. M. (2002). The self-concordance model of healthy goal-striving: When personal goals correctly represent the person. In E. L. Deci \& R. M. Ryan (Eds.), Handbook of self-determination research (pp. 65-86). Rochester, NY: The University of Rochester Press.

Spanier, D. (1987). Easy money: Inside the gambler's mind. London, UK: Secker \& Warburg.

Steiger, J. H. (1980). Tests for comparing elements of a correlation matrix. Psychological Bulletin, 87, 245-251.

Vallerand, R. J. (1997). Toward a hierarchical model of intrinsic and extrinsic motivation. Advances in Experimental Social Psychology, 29, 271-360.

Vallerand, R. J., \& Blanchard, C. M. (1999, June). Toward a psychology of passion. Paper presented at the 11th annual convention of the American Psychological Society, Denver, CO.

Vallerand, R. J., Blanchard, C., Mageau, G. A., Koestner, R., Ratelle, C. F., Léonard, M., Gagné, M., \& Marsolais, J. (2003). Les passions de l'âme: On obsessive and harmonious passions. Journal of Personality and Social Psychology, 85, 756-767.

Walker, M. B. (1992). The psychology of gambling. Oxford, UK: Pergamon.

Williams, E. J. (1959). The comparison of regression variables. Journal of the Royal Statistical Society, Series B, 21, 396-399. 